\title{
Enlightening Point of View Based on Potassium Channel “Origami Windmill” Model
}

\author{
Zuodong Sun * \\ Ya'ou Brain Science Institute of Heilongjiang province, Harbin 150090, China
}

\begin{abstract}
Abstrac:
Applying the $\mathrm{K}^{+}$channel origami windmill model principle, the whole process of action potential generation of nerve fiber cells and cardiomyocytes is explained reasonably. Its core view is: cell action potential decline phase, dominated by influx of potassium ions. This is contrary to the core idea of the traditional theory-ionic theory. According to ionic theory, cell action potential decline phase, dominated by outflow of $\mathrm{K}^{+}$ions.

In the face of such two opposing views, the author traces back to the source, combing and commenting on the basic theoretical research on the production mechanism of cell bioelectricity generation and the results of classical basic experiments. And a series of enlightening viewpoints are produced: 1 . Ionic theory has its preexistence deficiency; 2 . There are principle defects in GHK equation and H-H equation; 3. Ion channels may "same direction sharing"; 4. Sodium-potassium pumps, calcium pumps and so on May not exist.

The thesis's Point is falsifiable. If "cell action potential decline stage, dominated by outflow of $\mathrm{K}^{+}$ions" can be proved, all the points in this paper will not be true. On the contrary, the series of enlightening views in this paper will inevitably lead to a revolution in the field of life science. The viewpoint of this paper is not only closely related to the causes of human major diseases, treatment principles and methods, but also may have a profound impact on the future research direction of life science researchers.

So the author suggests that scholars in the field of life science should re sort out the existing bioelectricity knowledge system - eliminate the false, save the true and clear the source, especially focusing on the papers published by Hodgkin and Huxley in 1952; At the same time, it is necessary to reevaluate the scientificity and scientific value of membrane theory, ionic theory, GHK equation and $\mathrm{H}-\mathrm{H}$ equation, and put forward new theories based on Bernstein membrane theory, and establishing a new mathematical model of cell action potential.
\end{abstract}

Keywords: $\mathrm{K}^{+}$channel "origami windmill” model; action potential; sodium-potassium pump; ionic theory; GHK equation; H-H equation

The establishment of the $\mathrm{K}^{+}$channel "origami windmill" model ${ }^{[1]}$ has gone through the deduction process of practice-theory-re-practice-re-theory. Since 1994, the author has applied the transcranial electrical and transcranial magnetic electrical stimulation technology to invent a brain function rehabilitation therapeutic apparatus $(1995)^{[2,3]}$, a depression therapeutic apparatus $(2011)^{[4,5]}$, a Parkinson's disease therapeutic apparatus $(2011)^{[6,7]}$, Alzheimer's disease therapeutic apparatus ${ }^{[8,9]}$ (2014) and other

* Corresponding author: Zuodong Sun (E-mail: sunzuodong@pai314.com). 
encephalopathy rehabilitation treatment equipment are widely used in the clinical practice of cranial nerve diseases, and have achieved significant rehabilitation treatment effects. As the inventor, in order to clarify the treatment mechanism of equipment and the cause of severe cerebral disease, applying the principles of physical biology, "the theory of brain cell activation" ${ }^{[10]}$ (2015), "the theory of dove-like particles"[11] (2019), and " $\mathrm{K}^{+}$channel 'origami windmill' model" ${ }^{[1]}(2019)$ was put forward from the level of cell molecule.

Applying the principle of origami windmill model, the whole process of action potential generation of nerve fiber cells and cardiomyocytes has been explained reasonably ${ }^{[12,13]}$. Therefore, the core point of this paper is contrary to the ionic theory. That is cell action potential decline phase, dominated by influx of potassium ions. According to ionic theory ${ }^{[14]}$, cell action potential decline phase, dominated by outflow of $\mathrm{K}^{+}$ions. In the face of such two opposing views, the author traces back to the source, and combing on the basic theoretical research on the production mechanism of cell bioelectricity generation and the results of classical basic experiments which were after 1902. And the author also made some important comments. A series of enlightening views arising from this are related to the basic problems of life science. These views are not only closely related to the causes of major human diseases, treatment principles and methods, but also may have a profound impact on the future research direction of life science researchers.

\section{Basic Theory}

In theory, there are two theories about the mechanism of cell bioelectricity generation: One is the ionic theory proposed by Hodgkin school on the basis of Bernstein's membrane theory ${ }^{[15]}$; The other is the metamorphism theory put forward by the school of Насонов on the basis of Hermann's phase theory ${ }^{[16,17]}$. Among them, according to the metamorphic theory, there is no membrane potential inside or outside the resting cell membrane at all. When the cell is damaged or excited, because to protein denaturation, $\mathrm{K}^{+}$dissociation, then there is potential difference between the damaged or excited site and the normal site.

The reason why the metamorphic theory is not accepted by the general scholars is that there are few supporting experiments and many bioelectric phenomena can not be explained reasonably; The reason why ionic theory is accepted by most scholars is that it seems to be able to "satisfactorily" "explain" the generation mechanism bioelectricity and seems to be "supported" by a large number of experimental "facts".

Therefore, this paper focuses on the ionic theory, and the mathematical model based on the ionic theory. 


\subsection{Ionic theory}

In 1902, Bernstein put forward membrane theory, also known as preexistence theory. He believes that bioelectricity normally exists in biological tissues and does not depend on stimulation or excitation. The reason why the membrane potential is negative at rest is due to the high concentration of potassium ion in the membrane, the special permeability of the cell membrane to potassium ion, and the outflow of potassium ion leaving the negative charge in the cell. When nerve or muscle excited impulse occurs, the selective permeability of cell membrane disappears temporarily, that is to say, action potential is the manifestation of membrane potential disappearance.

However, after 1939, due to the improvement of experimental technology, many facts were found that could not be explained by membrane theory. For example, if the disappearance of action potential is only the disappearance of membrane potential, the maximum value of action potential will not exceed the membrane potential. Hodgkin and Huxley ${ }^{[18]}$ (1939) inserted microelectrodes into the large nerve fibers of squid, and directly measured the potential difference between the inner and outer membrane, and found the so-called "overshoot phenomenon" in the action potential (Figure 1). According to this, Hodgkin and Katz ${ }^{[14]}$ (1949) proposed the ionic theory based on the membrane theory and used it to explain the mechanism of bioelectricity.

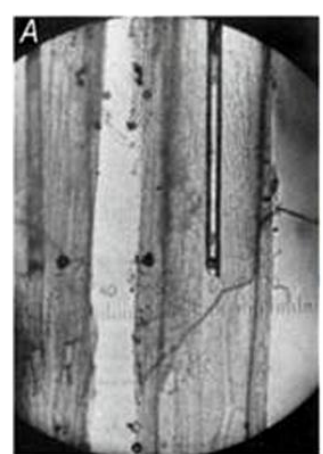

A

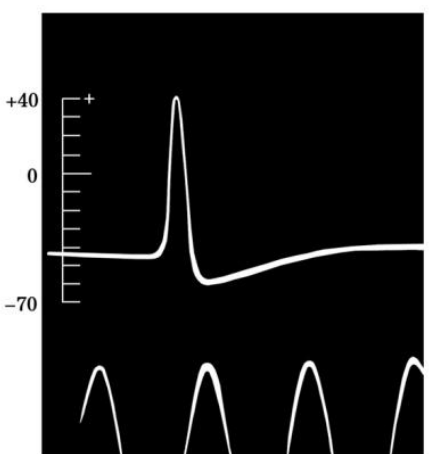

B

Figure 1 Intracellular recording of action potential of giant axon of squid[18]

Fig. A. Micrograph of the electrode inside the giant axon of squid (about $500 \mu \mathrm{m}$ in diameter). Two views of the same axon can be seen in the ingenious microscope designed by Huxley. In this way, the electrode can be observed from the front and the side simultaneously, which is very important to avoid the damage of the neuron membrane by the electrode. Fig. B. The first intracellular action potential recording.

According to ionic theory, bioelectricity occurs on both sides of cell membrane, and membrane potential is determined by ion movement. Because of the different numbers of various ions through the surface membrane under different physiological conditions, 
different membrane potentials appear. At rest, the permeability of cell membrane to $\mathrm{K}^{+}$, $\mathrm{Na}^{+}$and $\mathrm{Cl}^{-}$is different. The resting membrane potential is mainly determined by the equilibrium potential of potassium ion, that is "internal negative external positive". When excited, the permeability of the cell membrane to $\mathrm{K}^{+}, \mathrm{Na}^{+}$and $\mathrm{Cl}^{-}$changes. The action membrane potential is mainly determined by the balance potential of $\mathrm{Na}^{+}$, that is "positive inside and negative outside".

\section{Comments:}

The ionic theory proposed by the Hodgkin school is based on Bernstein's membrane theory. The membrane theory holds that "biological tissue has its own bioelectricity when there is no stimulation or excitement". This preexistential view may be true, but the ionic theory does not explicitly affirm it; Membrane theory holds that, "when resting, the potential inside the membrane is negative because the $\mathrm{K}^{+}$outflow causes the negative charge to stay inside the cell", and "when a nerve or muscle excites, the selective permeability of the cell membrane temporarily disappears", this point of view may be the wrong, ionic theory does not give a clear negative, instead, it has been further strengthened in the later research work. Whether it is membrane theory or ionic theory, the presenter has ignored the structure and characteristics of ion channels - the inlet and outlet channels are independent and the ion inlet and outlet channels are "same direction sharing", not found the essence of the cell action potential and the rules of ion exchange inside and outside the membrane - the membrane area is equal, and the number of ions is not equal.

According to the ionic theory, when the concentration of $\mathrm{K}^{+}$outside the membrane increases, the change of resting potential is in a linear relationship with the logarithm of the concentration of $\mathrm{K}^{+}$outside the membrane; When the concentration of extramembrane $\mathrm{Na}^{+}$changed, the change of action potential was in a linear relationship with the logarithm value of the concentration of extrambrane $\mathrm{Na}^{+}$. In fact, for cell membranes, a small change in charge can produce a large transmembrane potential difference, if the ion change amount of $100 \mathrm{mV}$ film voltage is $1.25 \times 10^{5}$ ions, it only causes the change of one in ten million of the intracellular ion concentration, this indicates that the change of membrane potential has almost no effect on ion concentration, so it is not a wise choice to try to quantitatively express the change of cell membrane potential through the change of ion concentration.

The opposite between the ionic theory and the principle of "origami windmill" model is also reflected in:

(1) according to the ionic theory, the membrane of a nerve or muscle cell membrane in its resting state has higher permeability to $\mathrm{K}^{+}$than other cations, and higher permeability to $\mathrm{Cl}^{-}$, while low permeability to $\mathrm{Na}^{+}$. According to the principle of 
"origami windmill" model, when the cell membrane is in resting state, both the E channel and the $\mathrm{L}$ channel are closed relative to $\mathrm{K}^{+}$and open relative to $\mathrm{Na}^{+}$.

(2) according to the ionic theory, when nerves or muscles are excited, membrane to $\mathrm{Na}^{+}$permeability increases suddenly and selectively, resulting in action potential. According to the principle of the "origami windmill" model, when the cell has an action potential, the rising phase: the $\mathrm{L}$ channel is open relative to $\mathrm{K}^{+}$, while the $\mathrm{E}$ channel is closed relative to $\mathrm{K}^{+}$; The falling phase: $\mathrm{E}$ channel is open relative to $\mathrm{K}^{+}$and $\mathrm{L}$ channel is closed relative to $\mathrm{K}^{+}$. E channel and $\mathrm{L}$ channel are always open relative to $\mathrm{Na}^{+}$.

\subsection{Mathematical model}

Building the mathematical models based on the ion theory, including: Goldman-Hodgkin-Katz (GHK) equation and Hodgkin-Huxley (H-H) equation ${ }^{[17,19-20]}$.

\subsubsection{GHK equation and resting potential}

According to ionic theory, when the cell membrane of nerve or muscle is in resting state, the permeability to $\mathrm{K}^{+}$is higher than that to other cations, to $\mathrm{Cl}^{-}$is also higher, and to $\mathrm{Na}^{+}$is lower. Therefore, according to the Gibbs Donnan equilibrium principle ${ }^{[21,22]}$, the potential difference between $\mathrm{K}^{+}$and $\mathrm{Cl}^{-}$on both sides of the membrane can be calculated by the Nernst equation ${ }^{[23]}$. Namely:

$$
E=\frac{R T}{F} \ln \frac{\left[K^{+}\right]_{o}}{\left[K^{+}\right]_{i}}=\frac{R T}{F} \ln \frac{\left[C l^{-}\right]_{o}}{\left[C l^{-}\right]_{i}}
$$

In the equation, E:Membrane potential, $\left[\mathrm{K}^{+}\right]_{\mathrm{o}} /\left[\mathrm{K}^{+}\right]_{\mathrm{i}}: \mathrm{K}^{+}$concentration ratio, $\left[\mathrm{Cl}^{-}\right]_{\mathrm{o}} /\left[\mathrm{Cl}^{-}\right]_{\mathrm{i}}: \mathrm{Cl}^{-}$concentration ratio, the subscripts "o" and "i" refer to extracellular and intracellular respectively. R: Universal gas constant. T: Absolute temperature. F: Faraday constant.

Theoretically, if the concentration of ions inside and outside the cell can be measured, it is not difficult to calculate the equilibrium potential of various ions. The approximate value of membrane potential calculated by Nernst equation is $75 \sim$ $100 \mathrm{mV}$. This is in accordance with the results of direct measurement of membrane potential by microelectrode technology. Especially for the nerves of crabs, the observed results are almost equal to the calculated values (Table 1) ${ }^{[17]}$.

Table 1 Example of resting membrane potential

\begin{tabular}{c|c|c}
\hline \multirow{2}{*}{ Tissue } & \multicolumn{2}{|c}{ Resting film potential (mV) } \\
\cline { 2 - 3 } & Observed value & Calculated value \\
\hline Squid axon & 61 & 74 \\
Sepia axon & 62 & 77 \\
Carcinus axon & 82 & 89 \\
\hline
\end{tabular}


However, when several ions are distributed in and out of the cell membrane at different concentrations, the equilibrium potential calculated by Nernst equation is far from the measured value. Thus, Hodgkin and Katz ${ }^{[14]}$ (1949) introduced constant electric field theory by Goldman ${ }^{[24]}$ (1943), they believe that the permeability of chloride ions cannot be ignored. So they improved the Nernst equation and developed a new set of formulas. They try to establish the relationship between the concentration gradients of three kinds of monovalent ions of $\mathrm{K}^{+} 、 \mathrm{Na}^{+} 、 \mathrm{Cl}^{-}$and the membrane potential, namely, the G-H-K equation:

$$
E m=\frac{R T}{F} \ln \frac{p_{\mathrm{Na}}\left[\mathrm{Na}^{+}\right]_{o}+p_{\mathrm{K}}\left[\mathrm{K}^{+}\right]_{o}+p_{\mathrm{Cl}}\left[\mathrm{Cl}^{-}\right]_{i}}{p_{\mathrm{Na}}\left[\mathrm{Na}^{+}\right]_{i}+p_{\mathrm{K}}\left[\mathrm{K}^{+}\right]_{i}+p_{\mathrm{Cl}}\left[\mathrm{Cl}^{-}\right]_{o}}
$$

In the equation, $\mathrm{E}_{\mathrm{m}}$ : Membrane potential, $\mathrm{p}$ : Permeability coefficient of each ion.

According to this formula and the concentration of sodium, potassium and chloride ions, the calculated membrane potential of the axon of squid is $59.5 \mathrm{mV}$, which is close to the measured value of $61 \mathrm{mV}$. Therefore, it is reasonable to use the ionic theory to explain the resting membrane potential.

\subsubsection{H-H equation and action potential}

According to the ionic theory, when the nerve or muscle is excited, the permeability of the membrane to $\mathrm{Na}^{+}$increases suddenly and selectively, thus generating action potential. According to Hodgkin and Huxley, the permeability of other ions, such as $\mathrm{Cl}^{-}$, can be ignored when $\mathrm{Na}^{+}$permeability is dominant. The magnitude of membrane potential mainly depends on the concentration of sodium ions inside and outside the membrane, namely:

$$
E_{\mathrm{Na}}=\frac{R T}{F} \ln \frac{\left[N a^{+}\right]_{i}}{\left[N a^{+}\right]_{o}}
$$

Theoretically, the calculation result should be equal to the height of action potential. In fact, the measured action potential is much smaller than the calculated value. Therefore, they have to find the "evidence" to support the ionic theory from the ion flow.

From 1950 to 1952, Hodgkin, Huxley and Katz (1952) used the voltage clamping technology of Cole (1949) to estimate the change of membrane conductance by measuring the current flowing through the membrane at different membrane potentials, and introduced Ohm's law to deduce the membrane conductance formula of an ion:

$$
G_{\mathrm{Na}}=\frac{I_{\mathrm{Na}}}{V-V_{\mathrm{Na}}}, \quad G_{\mathrm{K}}=\frac{I_{\mathrm{K}}}{V-V_{\mathrm{K}}}
$$


Among them, $\mathrm{G}_{\mathrm{Na}}, \mathrm{G}_{\mathrm{K}}$ : The conductance of sodium and potassium, $\mathrm{I}_{\mathrm{Na}}, \mathrm{I}_{\mathrm{K}}$ : The current of sodium and potassium, $\mathrm{V}$ : The membrane potential, $\mathrm{V}_{\mathrm{Na}}, \mathrm{V}_{\mathrm{K}}$ : The equilibrium potential of $\mathrm{Na}^{+}$and $\mathrm{K}^{+}$.

In order to further explain the generation and propagation of cell action potential, they used a set of equations to fit the data. The changes of membrane conductance $\mathrm{G}_{\mathrm{Na}}$ and $\mathrm{G}_{\mathrm{K}}$ are expressed as a function of membrane potential and time. Finally, they simulate action potential by solving a complex set of nonlinear dynamic differential equation.

$$
\begin{gathered}
I=C_{M} \frac{\mathrm{d} V}{\mathrm{~d} t}+\bar{g}_{\mathrm{K}} n^{4}\left(V-V_{\mathrm{K}}\right)+\bar{g}_{\mathrm{Na}} m^{3} h\left(V-V_{\mathrm{Na}}\right)+\bar{g}_{\mathrm{l}}\left(V-V_{1}\right) \\
\frac{\mathrm{d} n}{\mathrm{~d} t}=\alpha_{n}(1-n)-\beta_{n} n \\
\frac{\mathrm{d} m}{\mathrm{~d} t}=\alpha_{m}(1-m)-\beta_{m} m \\
\frac{\mathrm{d} h}{\mathrm{~d} t}=\alpha_{h}(1-h)-\beta_{h} h \\
\frac{\alpha}{2 R_{2}} \frac{\partial^{2} V}{\partial x^{2}}=C_{M} \frac{\partial V}{\partial t}+\bar{g}_{\mathrm{K}} n^{4}\left(V-V_{\mathrm{K}}\right)+\bar{g}_{\mathrm{Na}} m^{3} h\left(V-V_{\mathrm{Na}}\right)+\bar{g}_{1}\left(V-V_{1}\right)
\end{gathered}
$$

Or

$$
\frac{\alpha}{2 R_{2} \theta^{2}} \frac{\mathrm{d}^{2} V}{\mathrm{~d} t^{2}}=C_{M} \frac{\mathrm{d} V}{\mathrm{~d} t}+\bar{g}_{\mathrm{K}} n^{4}\left(V-V_{\mathrm{K}}\right)+\bar{g}_{\mathrm{Na}} m^{3} h\left(V-V_{\mathrm{Na}}\right)+\bar{g}_{\mathrm{l}}\left(V-V_{1}\right)
$$

The above formula is also Figure 2 (29) or (30). The H-H equation is a second-order nonlinear ordinary differential equation. The first item on the right side of formula (29) is capacitive current, $\alpha$ is the radius of the nerve fiber, $\mathrm{R}$ is the resistance in the axoplasm where the nerve fiber is located, $C_{M}$ is the capacitance of the membrane per unit area, $\mathrm{X}$ is the distance of current conduction along the fiber axis. It can be replaced by the product of conduction velocity $\theta$ and time $t$, and equation (29) becomes equation (30).

The second and third are the currents carried by $\mathrm{K}^{+}$and $\mathrm{Na}^{+}$. The fourth is the current carried by other ions through leakage conductance. $\mathrm{m}, \mathrm{n}$ and $\mathrm{h}$ are gated variables of ion channels, which change from initial value to steady value according to exponential time process. $\mathrm{m}, \mathrm{n}$ and $\mathrm{h}$ are respectively expressed by equation (7) (15) (16) of Fig.2, among them, $\alpha_{\mathrm{m}}$ and $\beta_{\mathrm{m}}$ are rate constants. In order to match the experimental data, the gating variables $m$ and $n$ appear in the third and fourth power, respectively. One explanation is that the activation of sodium conductance on the giant axon of squid involves three activated particles (m-gate) and one deactivated particle (h-gate); The activation of potassium conductance involves four activated particles (n-gate). Membrane depolarization activated $\mathrm{m}$-gate and $\mathrm{n}$-gate, and inactivated h-gate. 


\begin{tabular}{|c|c|c|c|}
\hline$I=C_{M} \frac{\mathrm{d} V}{\mathrm{~d} t}+I_{i}$ & $I_{i}=I_{\mathrm{Na}}+I_{\mathrm{K}}+I_{l}$ & $I_{\mathrm{Na}}=g_{\mathrm{Na}}\left(V-V_{\mathrm{Na}}\right)$ & $I_{\mathrm{K}}=g_{\mathrm{K}}\left(V-V_{\mathrm{K}}\right)$ \\
\hline$I_{l}=\bar{g}_{l}\left(V-V_{l}\right)$ & $g_{\mathrm{K}}=\bar{g}_{\mathrm{K}} n^{4}$ & $\frac{\mathrm{a} n}{\mathrm{~d} t}=$ & $\begin{array}{l}(8) \\
n=n_{\infty}-\end{array}$ \\
\hline$n_{\infty}=\alpha_{n} /\left(\alpha_{n}+\beta_{n}\right)$ & $\tau_{n}=1 /\left(\alpha_{n}+\beta_{n}\right)$ & \multicolumn{2}{|c|}{$\stackrel{(11)}{g_{\mathrm{K}}}=\left\{\left(g_{\mathrm{K} \infty}\right)^{t}-\left[\left(g_{\mathrm{K} \infty)^{t}}-\left(g_{\mathrm{K} 0}\right)^{t}\right] \mathrm{e} 2\right.\right.$} \\
\hline \multicolumn{2}{|c|}{$\alpha_{n}=0 \cdot 01(V+10) /\left[\exp \frac{V+10}{10}-1\right]$} & (13) $\beta_{n}=0 \cdot 125$ & 14) $g_{\mathrm{Na}}$ \\
\hline$\frac{\mathrm{d} m}{\mathrm{~d} t}=\alpha_{m}(1-m)-\beta_{m} m$ & ${ }^{(16)} \frac{\mathrm{d} h}{\mathrm{~d} t}=\alpha_{h}(1-h)-\beta_{h} h$ & \multicolumn{2}{|c|}{${ }^{(17)} \quad m=m_{\infty}-\left(m_{\infty}-m_{0}\right) \exp \left(-t / \tau_{m}\right)$} \\
\hline \multicolumn{2}{|c|}{$h=h_{\infty}-\left(h_{\infty}-h_{0}\right) \exp \left(-t / \tau_{h}\right)$} & \multicolumn{2}{|c|}{${ }^{199} g_{\mathrm{Na}}=g_{\mathrm{Na}}\left[1-\exp \left(-t / \tau_{m}\right)\right]^{3} \exp \left(-t / \tau_{h}\right)$} \\
\hline \multicolumn{2}{|c|}{$\alpha_{m}=0 \cdot 1(V+25) /\left(\exp \frac{V+25}{10}-1\right)$} & $\beta_{m}=$ & $m_{\infty}=$ \\
\hline$\stackrel{(23)}{\alpha_{h}}=0.07 \exp (V / 20)$ & \multicolumn{2}{|c|}{$\beta_{h}=1 /\left(\exp \frac{V+30}{10}+1\right)$} & $h_{\infty}$ \\
\hline \multicolumn{2}{|c|}{$\stackrel{(26)}{I=} C_{M} \frac{\mathrm{d} V}{\mathrm{~d} t}+\bar{g}_{\mathrm{K}} n^{4}\left(V-V_{\mathrm{K}}\right)+\bar{g}_{\mathrm{Na}} m^{3} h\left(V-V_{\mathrm{Na}}\right)+\bar{g}_{l}\left(V-V_{l}\right)$} & $i=\frac{1}{r_{1}+r_{2}} \frac{\partial^{2} V}{\partial x^{2}}$ & $i=\frac{1}{r_{2}} \frac{\partial^{2} V}{\partial x^{2}}$ or $I=\frac{a}{2 R_{2}} \frac{\partial^{2} V}{\partial x^{2}}$ \\
\hline \multicolumn{4}{|c|}{$\frac{a}{2 R_{2}} \frac{\partial^{2} V}{\partial x^{2}}=C_{M} \frac{\partial V}{\partial t}+\bar{g}_{\mathrm{K}} n^{4}\left(V-V_{\mathrm{K}}\right)+\bar{g}_{\mathrm{Na}} m^{3} h\left(V-V_{\mathrm{Na}}\right)+\bar{g}_{l}\left(V-V_{l}\right)$} \\
\hline \multicolumn{4}{|c|}{ (30) $\quad \frac{a}{2 R_{2} \theta^{2}} \frac{\mathrm{d}^{2} V}{\mathrm{~d} t^{2}}=C_{M} \frac{\mathrm{d} V}{\mathrm{~d} t}+\bar{g}_{\mathrm{K}} n^{4}\left(V-V_{\mathrm{K}}\right)+\bar{g}_{\mathrm{Na}} m^{3} h\left(V-V_{\mathrm{Na}}\right)+\bar{g}_{l}\left(V-V_{l}\right)$} \\
\hline \multicolumn{3}{|c|}{ (31) $\quad \frac{\mathrm{d}^{2} V}{\mathrm{~d} t^{2}}=K\left\{\frac{\mathrm{d} V}{\mathrm{~d} t}+\frac{1}{C_{M}}\left[\bar{g}_{\mathrm{K}} n^{4}\left(V-V_{E}\right)+\bar{g}_{\mathrm{Na}_{\mathbf{s}}} m^{2} h\left(V-V_{\mathrm{Na}_{\mathrm{a}}}\right)+\bar{g}_{l}\left(V-V_{l}\right)\right]\right\}$} & $(32)$ \\
\hline \multicolumn{3}{|c|}{ (33) $\frac{\mathrm{d} V}{\mathrm{~d} t}=-\frac{1}{C_{M}}\left\{\bar{g}_{\mathrm{K}} n^{4}\left(V-V_{\mathrm{K}}\right)+\bar{g}_{\mathrm{Na}} m^{2} h\left(V-V_{\mathrm{Na}_{\mathbf{a}}}\right)+\bar{g}_{l}\left(V-V_{l}\right)\right\}+\frac{z}{K}$} & $\theta=\sqrt{ }(K$ \\
\hline \multicolumn{4}{|c|}{$\delta I=C_{M} \frac{\mathrm{d} \delta V}{\mathrm{~d} t}+\bar{g}_{\mathrm{K}} n_{0}^{4} \delta V-4 \bar{g}_{\mathrm{K}} n_{0}^{3} V_{\mathrm{K}} \delta n+\bar{g}_{\mathrm{Na}} m_{0}^{3} h_{0} \delta V-3 \bar{g}_{\mathrm{Na}} m_{0}^{2} h_{0} V_{\mathrm{Na}} \delta m-\bar{g}_{\mathrm{Na}} m_{0}^{3} V_{\mathrm{Na}} \delta h+\bar{g}_{l} \delta V$} \\
\hline \multicolumn{4}{|c|}{ (36) $\frac{\mathrm{d} \delta n}{\mathrm{~d} t}=\frac{\partial \alpha_{n}}{\partial V} \delta V-\left(\alpha_{n}+\beta_{n}\right) \delta n-n_{0} \frac{\partial\left(\alpha_{n}+\beta_{n}\right)}{\partial V} \delta V \quad$ or $\quad\left(p+\alpha_{n}+\beta_{n}\right) \delta n=\left\{\frac{\partial \alpha_{n}}{\partial V}-n_{0} \frac{\partial\left(\alpha_{n}+\beta_{n}\right)}{\partial V}\right\} \delta V$} \\
\hline
\end{tabular}

Figure 2 Part of the mathematical formula used by Hodgkin and Huxley to derive the $\mathrm{H}-\mathrm{H}$ equation ${ }^{[25]}$

The H-H equation contains the following series of events: Membrane depolarization results in the rapid activation of $\mathrm{m}$-gate and the rapid increase of inward sodium current. The activation of m-gate leads to further depolarization, and this positive feedback forms the fast rising phase of action potential. Then, the inward sodium current was caught up with the outward potassium current, which led to the repolarization of membrane potential.

Hodgkin and Huxley believe that by solving these equations, not only the experimental results of their voltage clamping potential can be calculated, but also the generation and propagation process of action potential without clamping voltage can be obtained - the shape, amplitude and conduction velocity of action potential can be obtained. 


\section{Comments:}

The mathematical model established according to the ionic theory - GHK equation and h-h equation have congenital defects.

GHK equation refers to Nernst equation and tries to establish the relationship between ion concentration gradient and membrane potential. It is believed that $\mathrm{Cl}^{-}$, like $\mathrm{Na}+$ and $\mathrm{K}^{+}$, "go in and out together" inside and outside the cell membrane, and its defects are fundamental, and the reasons are as follows: (1) A small change in charge can cause a large transmembrane potential difference in the cell. The corresponding change in ion concentration can only cause a change of one in ten million of the intracellular ion concentration. It is inappropriate to use the change in ion concentration to reflect the change in cell membrane potential; (2) Due to the large diameter (334pm) of $\mathrm{Cl}^{-}$in vivo living cells, it is not active in the ion exchange process inside and outside the membrane. It is unscientific to take the change of $\mathrm{Cl}^{-}$ concentration as the main parameter or variable of the equation;(3) according to the results of the actual observed in table 1, and application of GHK equation calculated value is nearly equal, and therefore thinks ionic theory was applied to the interpretation of the resting membrane potential is reasonable, this is a very low-level mistakes, because the actual value of membrane potential is marked with a "-", the designer of GHK equation did not understand the real meaning of membrane potential as a physical quantity with a “-”.

$\mathrm{H}-\mathrm{H}$ equation, is only an empirical equation, not a reliable molecular model, there is no linear relationship between each data element, and references to ohm's law, the cell membrane as a series of resistance, battery and capacitor connected into a circuit, eventually because of too many principles and parameters, makes the solution to the problem is complicated and difficult to understand and use phenomenon explain phenomenon, cannot really reflect the essence and regulation of cell bioelectricity phenomenon.

For example, when calculating the potential difference caused by the difference in the concentration of transmembrane ions, Gibbs-Donnan equilibrium principle, fixed field theory, Nernst equation, cable equation, Fick law, etc. is quoted; When calculating the probability of an ion channel opening, gibbs distribution, boltzmann equation and simple spring principle etc. is quoted.

The Gibbs-Donnan equilibrium principle applies only when there is no active transshipment of ions and selective permeability of no membranes, cell membranes are considered to have active transshipment and selective permeability. The application of Nernst equation does not involve ion permeability, nor ion selective permeability. The theory of fixed field assumes that the potential difference between the two sides of the 
membrane remains constant, and that the flow of ions through the membrane is influenced by its diffusion velocity and electric field. Fick law shows the linear relationship between flow density and concentration gradient per unit time, while the diffusion equation describing the migration of substances from the high concentration region to the low concentration region is derived from Fick law and the conservation of particle number. Simple spring is the most basic physical model of natural science, such as the fluctuation of cell membrane, which can be used, but it is not applicable to the quantitative expression of cell action potential.

Paradoxically, these principles and formulas are cited as reasons for not being appropriate, instead was cited as a reason to cite. On this basis, the GHK equation and h-h equation are derived without scientific basis. "Four parameters draw the elephant, five parameters shake the nose", with the lack of scientific basis of mathematical model to explain a natural science phenomenon, no matter how perfect and mysterious this explanation, its scientific nature and applicability should be questioned. It starts with ohm's law, but it turns out it's not consistent with ohm's law.

Therefore, it is inevitable that the ionic theory and the GHK equation and $\mathrm{H}-\mathrm{H}$ equation established according to the ionic theory will be completely negated and discarded. At the same time, it is necessary to put forward a new theory and establish a new mathematical model based on the new theory, so as to explain the generation mechanism of cell bioelectricity in a scientific and reasonable way.

\section{Basic experiment}

Since both the ionic theory and the GHK equation and $\mathrm{H}-\mathrm{H}$ equation based on the ionic theory are congenital and principled defects, why do they appear repeatedly in our existing bioelectricity knowledge system? They can be regarded as classical basic theories from hypothesis to theory to mathematical model. In universities, people learn these theories, and they are written in the authoritative higher textbooks of the world $^{[26-30]}$ or the mainstream biology textbooks of high school ${ }^{[21,31-35]}$. Without a large number of "supporting" experimental data provided by later scholars, this is absolutely impossible. These scholars, of course, also include Hodgkin, Huxley and Katz himself.

\subsection{Classical experiment}

According to the ionic theory, when the concentration of $\mathrm{K}^{+}$outside the membrane increases, the change of resting potential and logarithm value of $\mathrm{K}^{+}$concentration outside membrane are linear. When the concentration of $\mathrm{Na}^{+}$outside the membrane changs, the change of action potential and logarithm value of $\mathrm{Na}^{+}$concentration outside membrane are linear. For this reason, later scholars have done a lot of basic 
experiments. These experimental results are interpreted as experimental "evidence" to support ionic theory.

\subsubsection{Experiment on the relationship between resting potential and $\mathrm{K}^{+}$concentration}

Curtis and Cole ${ }^{[36]}$ (1949) experimented on the greater nerve membrane of squid, Ling and Gerard ${ }^{[37]}$ (1949) experimented on frog muscle, Huxley and StäMpfli ${ }^{\text {[38-39] }}$ (1951) experimented on myelinated nerve fibers of frogs in vitro, these experiments prove: when the concentration of $\mathrm{K}^{+}$outside the membrane increases, the change of resting potential and logarithm value of $\mathrm{K}^{+}$concentration outside membrane are linear. However, when Lorente de Nó ${ }^{[40]}$ (1947) conducted the experiment with the frog neural stem, it was found that when the concentration of $\mathrm{K}^{+}$outside the membrane is increased, the change rate of resting potential is very slow. Therefore, there is no or little relationship between resting potential and $\mathrm{K}^{+}$concentration. They are not simple linear relationships.

However, Feng Depei and Liu Yumin ${ }^{[41,42]}$ (1949) studied the neural stem without sheath, and found that the $\mathrm{K}^{+}$concentration outside the membrane was still in a linear relationship with the resting potential. In their view, the problem with Lorente de Nó's experiment is that the specimen used has a sheath of connective tissue, which is not easily penetrated by ions.

Since then, Feng Depei and Liu Yumin ${ }^{[43,44]}$ (1951, 1953) have made further experiments. When the $\mathrm{K}^{+}$concentration of the surrounding solution is increased gradually, the logarithm of the ratio of nerve potential to the $\mathrm{K}^{+}$concentration inside and outside the membrane is linear, therefore, they infer that the membrane potential in high $\mathrm{K}^{+}$solution is Gibbs Donnan ${ }^{[21,22]}$ potential.

$\operatorname{Adrian}^{[45]}$ (1956) put the frog muscle fiber in hypertonic solution to make the water in the fiber escape, so as to increase the $\mathrm{K}^{+}$concentration in the membrane. It turns out that the change of membrane potential and logarithm value of $\mathrm{K}^{+}$concentration outside membrane are linear. That is to say, when the concentration of $\mathrm{K}^{+}$in the membrane increases, the membrane potential increases, and vice versa.

When Baker ${ }^{[46]}$ (1962) removed the axoplasm from the large axon and filled the membrane with $\mathrm{NaCl}$ instead of $\mathrm{KCl}$, the membrane potential could be reduced from $50 \mathrm{mV}$ to $0 \mathrm{mV}$. When $\mathrm{KCl}$ was restored, the membrane potential was also restored. When the $\mathrm{K}^{+}$concentration in the membrane is not too high, the relationship between $\mathrm{K}^{+}$concentration and resting membrane potential follows Nernst equation. But when the $\mathrm{K}^{+}$concentration is too high, it will not follow the Nernst equation. When $\mathrm{KCl}$ is replaced by other potassium salts (such as potassium sulfate, etc.), it has little effect on resting membrane potential, so it shows that resting membrane potential is mainly affected by $\mathrm{K}^{+}$. 


\subsubsection{Experiment on the relationship between action potential and $\mathrm{Na}^{+}$concentration}

Hodgkin $^{[39]}$ (1951) et al. proved the following facts on the squid's nerve, frog's sartorius muscle and nerve. When the concentration of $\mathrm{Na}^{+}$outside the membrane changs, the change of action potential and logarithm value of $\mathrm{Na}^{+}$concentration outside membrane are linear. But the membrane potential calculated by Nernst equation is much larger than the action potential measured in practice.

So, they have another explanation for the flow of ions.

They used isotopes to measure the flow of $\mathrm{K}^{+}$and $\mathrm{Na}^{+}$per unit area (square centimeter) during each impulse and at rest (Tables 2 and 3$)^{[17]}$. Take the axon of squid as an example, nerve impulse causes $\mathrm{Na}^{+}$to flow into the cell membrane in large numbers. It flows into $10.3 \mu \mu \mathrm{mol}$ only in a few milliseconds. However, a large amount of $\mathrm{Na}^{+}$also flowed out of the cell membrane $(6.6 \mu \mu \mathrm{mol})$. The $\mathrm{Na}^{+}$flowing in is more than that flowing out ( $3.7 \mu \mu \mathrm{mol}$ more). Moreover, the impulse can also cause a large amount of $\mathrm{K}^{+}$flow (outward $4.7 \mu \mu \mathrm{mol}$, inward $0.4 \mu \mu \mathrm{mol}$ ). More $\mathrm{K}^{+}$flowed outward than inward (4.3 $\mu \mu \mathrm{mol}$ more). Cole (1949), Hodgkin, Huxley and Katz ${ }^{[47]}$ (1952), applied voltage clamping technology to the axon experiment of squid, and obtained the ion flow of nerve fibers when excited. They experimented with choline ions instead of $\mathrm{Na}^{+}$in seawater to remove the effects of $\mathrm{Na}^{+}$flow. They obtained the variation of membrane current at different fixed voltages.

Table 2 Ion flow in resting state

\begin{tabular}{c|c|c|c}
\hline \multirow{2}{*}{ Ion } & \multicolumn{2}{|c|}{ Ion flow $\left(\mu \mu \mathrm{mol} / \mathrm{cm}^{2} / \mathrm{sec}\right)$} & \multirow{2}{*}{$\begin{array}{c}\text { Ratio of outward and } \\
\text { inward flow }\end{array}$} \\
\cline { 2 - 3 } & Inward & Outward & $1: 0.3$ \\
\hline $\mathrm{K}^{+}$ & 17 & 58 & $1: 2.0$ \\
$\mathrm{Na}^{+}$ & 61 & 31 & \\
\hline
\end{tabular}

Table 3 Ion flow rate in active state

\begin{tabular}{c|c|c|c}
\hline \multirow{2}{*}{ Ion } & \multicolumn{2}{|c|}{$\begin{array}{c}\text { Ion flow } \\
\mu \mu \mathrm{mol} / \mathrm{cm}^{2} / \mathrm{imp}\end{array}$} & $\begin{array}{c}\text { Net flow } \\
\mu \mu \mathrm{mol} / \mathrm{cm}^{2} / \mathrm{imp}\end{array}$ \\
\cline { 2 - 4 } & Inward & Outward & $\begin{array}{c}\text { Difference of internal and } \\
\text { external flow }\end{array}$ \\
\hline $\mathrm{K}^{+}$ & 0.4 & 4.7 & 4.3 (Lose) \\
$\mathrm{Na}^{+}$ & 10.3 & 6.6 & 3.7 (Get) \\
\hline
\end{tabular}

\subsubsection{Experiment that should not be ignored}

In order to explain the metamorphic theory, Насонов, the proponent of metamorphic theory, made the following experiments in $1944^{[16,17]}$. He placed the muscle in the 
sarcoplasma, and the two poles of a pair of electrodes on the muscle surface and in the sarcoplasma (Figure 3). According to the membrane theory or ionic theory, it should not damage the potential or membrane potential, because sarcoplasma is only an electrolyte conductor outside the normal membrane. However, the experimental results show that the myoplasm is similar to the injured site, and has potential difference compared with the normal site, but has nothing to do with the damage of the membrane. As for the reason of the potential increasing gradually, he thought it was due to a time course for the ions to penetrate into the cell membrane and then to the protein. As for the "overshoot phenomenon" seen in the membrane theory, the metamorphic theory holds that it does not exist at all. That's just because you can't release all the $\mathrm{K}^{+}$when you're injured, but you can release all the $\mathrm{K}^{+}$when you're excited.

In addition, Lorente de Nó(1947), using the experimental results of frog nerve trunk, found that when $\mathrm{K}^{+}$concentration outside the membrane was increased, the resting potential changed very slowly. Therefore, it was believed that the resting potential had No relationship with the surrounding $\mathrm{K}^{+}$concentration or had little relationship with it, rather than a simple linear relationship. Baker (1962) experiment showed that the relationship between $\mathrm{K}^{+}$concentration and resting membrane potential was consistent with the Nernst equation when the $\mathrm{K}^{+}$concentration was not too high in the membrane, and the relationship was not consistent with the Nernst equation when the $\mathrm{K}^{+}$ concentration was too high.

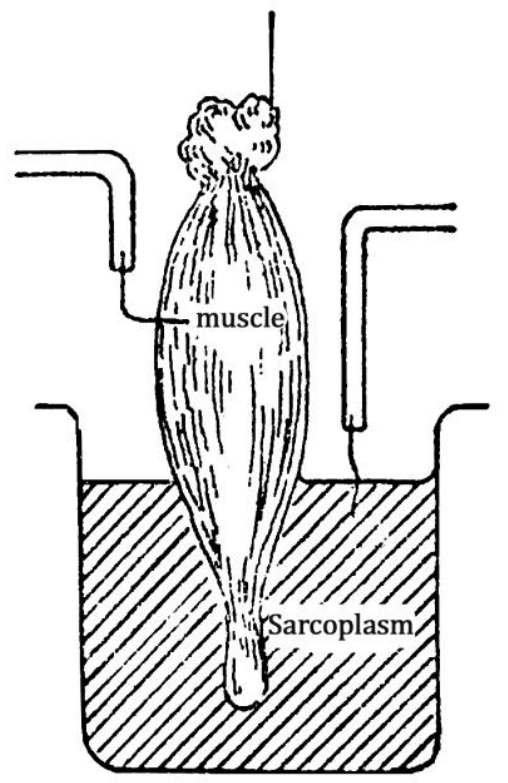

Figure 3 Shows the experimental setup without membrane potential 


\section{Comments:}

Most of these experiments are carried out on isolated specimens leaving the body. In theoretical calculation, it is assumed that the ion permeability of the sample is in a stable state. But in fact, the permeability of living cells to ions under normal physiological conditions is not stable, and it has selective permeability. So the so-called classical experiments described above, it is far fetched to regard them as "evidence" to support the theory of ions. Some even contradict themselves.

The cell membrane samples leaving the body are no longer selective and permeable. Under abnormal physiological conditions ( isolated specimens leaving the body ), the enzyme activity of cells will decrease or disappear, such as sodium potassium ATPase and calcium ATPase. In particular, the inactivation of the enzyme protein embedded in the cell membrane channel is equivalent to the loss of selective permeability of the membrane. Although the ion diffusion inside and outside the cell membrane is closely related to its concentration, the cell membrane is no longer the "itself" of living cells at this time.

For example, the experiments byLorente de Nó(1947), the experiments Feng Depei and Liu Yumin (1949), while providing the so-called supporting "evidence" for the ionic theory, they also proved that the in vitro specimen experiment is not the real reflection of living cells. It shows that the application of GHK equation and $\mathrm{H}-\mathrm{H}$ equation is unscientific. Насонов (1944) experiment, not only illustrates the extracellular fluid is electrically neutral, also illustrates the cell action potential has nothing to do with the changes of extracellular fluid ion concentration or, at the same time by accident for the pre-existence of the doctrine of membrane theory viewpoint provides supporting evidence, proved that the main point of membrane theory, namely: the biological tissue without stimulus or excitement, bioelectricity itself exist. The metamorphism theory put forward by the school of Насонов also has some advantages in the understanding of "overshoot phenomenon", which is considered that "overshoot phenomenon" does not exist at all.

In addition, Lorente de Nó(1947) may have correctly interpreted the experimental results in part: normal parts should be electrically neutral, such as the outer surface of cell membrane and extracellular fluid, and membrane potential may occur on the inner surface of cell membrane. The ionic theory holds that "bioelectricity occurs on the inside and outside of the cell membrane", whether this view is correct or not is debatable. Baker (1962) experimental results also showed that it was inappropriate to use Nernst equation for membrane potential calculation. 


\subsection{Pump and $\mathrm{K}^{+}$leakage channel}

In the application of ionic theory to explain the mechanism of bioelectricity, there is a key problem that cannot be avoided. Namely, in the process of action potential generation, how to ensure that the $\mathrm{K}^{+}, \mathrm{Na}^{+}, \mathrm{Ca}^{2+}$ plasma of "inside out" and "outside in" flows back to the original initial state before entering the next process. For this reason, scholars have made many conjectures and experiments.

\subsubsection{The origin of sodium potassium pump}

How can the influx sodium ions and the outflow potassium ions recover to the original state before entering the next process? Some people speculate that there must be sodium potassium pump to maintain the resting membrane potential. Hut ${ }^{[48]}$ (1935) used frog skin as a membrane to do experiments. It can be seen that sodium ions permeate from outside the membrane (the concentration of sodium ions is very low). $\operatorname{Krogh}^{[49]}$ (1937) observed that the frog skin could take sodium ions into the body from a very dilute $\mathrm{NaCl}$ solution $(10 \sim 5 \mathrm{~mol} / \mathrm{L})$, and the difference between the internal and external concentration of sodium ions was about 10000 times.

Dean $^{[50]}$ (1941) proposed the concept of sodium pump based on the previous work. Conway ${ }^{[51]}$ (1957) imagined that in the process of cell evolution, $\mathrm{Na}^{+}$was excluded to maintain osmotic pressure, and membrane potential was generated. In his research, he found that for every three $\mathrm{Na}^{+}$pumped out, he took in two $\mathrm{K}^{+}$. Skou ${ }^{[52]}$ (1957) found that the sodium potassium pump was $\mathrm{Na}^{+}-\mathrm{K}^{+}$-ATPase. Deleze ${ }^{[53]}$ (1960) suggested that sodium potassium pump was directly related to the maintenance of resting potential. Later, the researchers found that the exchange proportion of $\mathrm{Na}^{+}$and $\mathrm{K}^{+}$was 3: 2, which solved the problem of potassium ion reflux and sodium ion efflux, but also produced the contradiction of electric charge. Therefore, the pump with the exchange proportion of $\mathrm{Na}^{+}$and $\mathrm{K}^{+}$of 1: 1 is put forward. The pump with the exchange proportion of $\mathrm{Na}^{+}$and $\mathrm{K}^{+}$of 3: 2 is called "generating pump", and the pump with the exchange proportion of $\mathrm{Na}^{+}$and $\mathrm{K}^{+}$of $1: 1$ is called "neutral pump".

In the face of so many contradictions, scholars give another explanation: "The generating pump can directly play a role because it can change the membrane potential itself, while the neutral pump can only change the ion composition in the cell to indirectly play a role in the membrane potential". At this point, sodium potassium pump is no longer a theoretical guess. In the process of "conjecture" and "experiment" by scholars, its electricity generation and the characteristics of the outgoing current caused by it are "clarified" and "confirmed" step by step.

But the fact is that Hodgin himself had seriously suspected the existence and function of sodium potassium pump ${ }^{[54,55]}$. Hodgkin and Huxley (1947) pointed out in his discussion about overshoot phenomenon that, if the rate of sodium ions entering the 
cell is large enough to explain the rapid rise of membrane potential during nerve excitation, the energy needed to pump so much sodium out of nerve cells would far exceed the amount of oxygen consumed by the nerve as we know it.

\subsubsection{The origin of calcium pump and sodium calcium exchanger}

In order to keep the concentration of calcium in cells low and let the calcium in the inner flow out in time, it is speculated that there is a calcium pump. Setsuro and Lipmann $^{[56]}$ (1962) found that calcium pump is also an ATPase. It is ATP that drives $\mathrm{Ca}^{2+}$ pump to pump calcium ions out of the cell actively, and the exchange proportion of sodium and calcium is 3: 1 . Later, it was found that the function of calcium pump was weak, so some people proposed that the intracellular calcium outflow depends on the sodium and calcium exchange mechanism. Reuter and Seitz ${ }^{[57]}$ (1968) found the sodium calcium exchanger of cardiomyocytes. Hilgman ${ }^{[58]}$ (1990) used the patch clamp technique in inside-out mode on the giant myocardial cell membrane. On this huge membrane, if the concentration of $\mathrm{Ca}^{2+}$ in the intracellular fluid (perfusion fluid) increases, there will be an inward current; When the concentration of $\mathrm{Ca}^{2+}$ in the extracellular fluid increases, there will be an outward current. In this specimen, it seems that the regulatory effect of intracellular $\mathrm{Ca}^{2+}$ on sodium calcium exchanger has been confirmed, and $\mathrm{Na}^{+}$dependent inactivation has been found. After treatment with chymotrypsin, the function of both the regulation of $\mathrm{Ca}^{2+}$ and $\mathrm{Na}^{+}$dependent inactivation was lost.

\subsubsection{The origin of $\mathrm{K}^{+}$leakage channel}

According to the ionic theory, the permeability of $\mathrm{K}^{+}$is the highest among all kinds of ions in cell membrane resting state. It suggests that there is a continuously open non gated $\mathrm{K}^{+}$channel in the cell membrane, such as, there is a $\mathrm{K}^{+}$leakage channel in the nerve cell membrane. At rest, the $\mathrm{K}^{+}$permeability of this channel is about $50 \sim 100$ times that of $\mathrm{Na}^{+}$. The results of Hodgkin and Huxley (1939) experiments show that the measured resting potential is very close to the calculated $\mathrm{K}^{+}$equilibrium potential, but far from the $\mathrm{Na}^{+}$equilibrium potential. The change of $\mathrm{K}^{+}$concentration gradient on both sides of the membrane can also cause the corresponding change of resting potential. Thus "confirmed" the formation of resting potential, mainly due to the greater permeability of the cell membrane to $\mathrm{K}^{+}$and the diffusion of $\mathrm{K}^{+}$to the outside of the cell.

In order to restore the action potential to the initial state of the first phase before entering the next phase, they speculated that the cell membrane must also contain a set of $\mathrm{K}^{+}$leakage channels called $\mathrm{K}^{+}$leakage channels. Regardless of the conditions inside and outside the cell, these channels flicker randomly between the "open" and "closed" states. When the channels are open, $\mathrm{K}^{+}$is allowed to flow freely, and these channels 
are considered to be the main ion channels of cell membrane opening in resting state. Because in resting state, the permeability of cell membrane to $\mathrm{K}^{+}$is much higher than other ions. In their opinion, the difference between $\mathrm{K}^{+}$leakage channel and sodium potassium pump is as follows: $\mathrm{K}^{+}$leakage channel has higher permeability to $\mathrm{K}^{+}$and lower permeability to $\mathrm{Na}^{+}$. They both go in and out of each other in the similar quantity, and neither of them generates electric charge; The sodium potassium pump has the function of producing electric charge, and each time it runs, it adds one positive charge outside the cell.

\section{Comments:}

Sodium-potassium pump, calcium pump, sodium calcium exchanger and $\mathrm{K}^{+}$leakage channel are many conjectures of applying ionic theory to explain the mechanism of bioelectricity. That leads to the "ionic theory" can not "justify itself", and also shows that the existence of sodium potassium pump, calcium pump and sodium calcium exchanger is unreasonable. The mechanism of origami windmill model was used to explain the results of action potential experiments. In this process, sodium-potassium pump, calcium pump and sodium calcium exchanger were not involved. It shows that the existence of sodium-potassium pump, calcium pump and sodium calcium exchanger is unnecessary. If "neutral pump" exists, it is equivalent to denying the function of sodium-potassium pump; If $\mathrm{K}^{+}$leakage channel exists alone, it is equivalent to negating ionic theory. $\mathrm{K}^{+}$leakage channel shall belong to " $\mathrm{L}$ channel".

\section{Enlightening point of view}

According to the ionic theory, it is impossible to explain the mechanism of action potential of nerve fiber cells and cardiac myocytes scientifically and reasonably. According to the origami windmill model can reasonably explain the whole process of action potential of nerve fiber cells and myocardial cells. After combing the basic theoretical research and basic classical experiments of cell bioelectricity, the author has produced a series of enlightening views. These views relate to the basic problems of life science.

\subsection{The theory of ions has its pre-existenced deficiency}

The basis of the ionic theory is membrane theory, which does not explicitly affirm the view that membrane theory may be correct, nor explicitly negate the view that membrane theory may be wrong. Whether it is membrane theory or ionic theory, has ignored the structure and characteristics of ion channels - the inlet and outlet channels are independent and the ion inlet and outlet channels are "same direction sharing", not found the essence of the cell action potential and the rules of ion exchange inside and outside the membrane - the membrane area is equal, and the number of ions is not 
equal, this led to a series of misguided experiments, which made the methods of solving the problem more and more complicated and difficult to understand, logically incoherent, and contradictory to the experimental results.

According to the ion theory, the rising phase of action potential is dominated by $\mathrm{Na}^{+}$ internal flow. The theoretical calculation result is continuous depolarization, and the maximum positive value of the rising phase is much larger than the measured value, which cannot be explained.The falling phase of action potential is dominated by $\mathrm{K}^{+}$ outflow, and the theoretical calculation result is continuous repolarization. The minimum negative value of the falling phase is much less than the measured value, which is also unexplained. Later scholars tried to justify the ionic theory, also inherited the theory of membrane, namely, "when the excited impulse occurs in the nerve or muscle, the selective permeability of the cell membrane temporarily disappears."

Paradoxically, the view that "action potential is the manifestation of the disappearance of membrane potential" in the membrane theory was once denied by Hodgkin et al. because it could not explain the so-called "overshoot phenomenon" in the action potential, so the ionic theory was proposed. In fact, the ionic theory may be wrong about the so-called "Overshoot" phenomenon observed by experiments. The so-called "Overshoot" phenomenon should be the rule of bioelectricity activity of normal cells.

Applying the ionic theory, the forward deduction cannot be logically self-consistent; The reverse deduction, before the next period can not be reduced to the initial state of action potential. The current situation of ionic theory is the same as that of Ptolemy's "geocentrism theory" [59]. In order to maintain the geocentric theory, scientists added dozens of "epicycles" and "equal epicycles" to the existing system when the theoretical calculation results are inconsistent with the measured data. As a result, the geocentric theory still cannot be justified. But the system is becoming more and more complex and incomprehensible.

\subsection{There are principle defects in GHK equation and $\mathrm{H}-\mathrm{H}$ equation}

It is wrong to use Gibbs Donnan equilibrium principle and the theory of constant electric field theory in GHK equation, and it is not suitable to use Nernst equation for calculation. The H-H equation, which uses Ohm's law and membrane conductance, seems reasonable, but in fact, it makes a wrong direction. It led the research work of later scientists astray. It takes the concentration changes of $\mathrm{Na}^{+}, \mathrm{Cl}^{-}, \mathrm{K}^{+}, \mathrm{Ca}^{2+}$ and other ions as the main parameters or variables of the model, which is the fatal defect of GHK equation and $\mathrm{H}-\mathrm{H}$ equation.

Hodgkin and Huxley think that by solving a set of complex nonlinear dynamic differential equations, not only the experimental results of voltage clamping potential 
can be calculated, but also the generation and propagation process of action potential without clamping voltage can be obtained. That's not the case. In a single cell, the interval between the current action potential and the next action potential cannot be equal to the time when the action potential propagates between one cell and another. For example, does the propagation of action potential on the axon without myelin consider the existence or real function and significance of nodes of Ranvier? Can nerve fibers separated by nodes of Ranvier and nodes of Ranvier be regarded as independent cells? It is not clear whether each cell is absolutely synchronous with other cells when action potential occurs, but it should not be the relationship of mutual conduction or transmission. Perhaps, when action potential occurs between cells and other cells, there will be a time difference due to the asynchrony. This time difference is misunderstood as the conduction or transmission of action potential between cells.

Previously, the H-H equation has been questioned by Thomas heimburg and other scholars of Copenhagen University ${ }^{[60]}$. Thomas heimburg et al. found that all the experiments of Hodgkin and Huxley on neural conduction process in 1949 could not be repeated. Thomas heimburg et al selected the ventral neurons of earthworm and lobster for the experiment. They used electrodes to stimulate both ends at the same time, and then recorded the potential difference after the signal collided. The results show that it is not the "potential difference caused by the change of ion concentration" previously thought. Whether it's on earthworm's myelinated nerve fibers or lobster's unmyelinated nerve fibers, the result is that the speed and shape of the signal don't change after the collision. Whether it was the myelin fibers of an earthworm or the unmyelin fibers of a lobster, the signals did not change in speed or shape after the collision, thus negating the relationship between action potentials transmitting or spreading from cell to cell.

\subsection{Ion channels may "same direction sharing"}

The cell membrane is mainly composed of lipid and protein. Bernstein ${ }^{[15]}$ (1902) put forward the theory of membrane and speculated that "the cell membrane has special permeability to $\mathrm{K}^{+}$. Agre $^{[61]}$ (1988) successfully isolated aquaporin Mackinson ${ }^{[62]}$ (1998) measured the three-dimensional structure of $\mathrm{K}^{+}$channel.

Both the $\mathrm{H}_{2} \mathrm{O}$ channel and $\mathrm{K}^{+}$channel are proteins that span the phospholipid bilayer of cell membrane. We compared and analyzed the stereostructure diagram of $\mathrm{H}_{2} \mathrm{O}$ channel with $\mathrm{K}^{+}$channel, $\mathrm{Na}^{+}$channel, $\mathrm{Ca}^{2+}$ channel protein (Figure 4) and channel subunit structure (Figure 5), and it is not difficult to find that they are very similar. In other words, $\mathrm{H}_{2} \mathrm{O}$ channel, $\mathrm{K}^{+}$channel, $\mathrm{Na}^{+}$channel and $\mathrm{Ca}^{2+}$ channel may belong to the same type of channel, namely "E channel". The stereoscopic structure of these four channel proteins is likely to be the four different manifestations of the same or the same type of "e channel" in different states, instead of four different ion channels. 


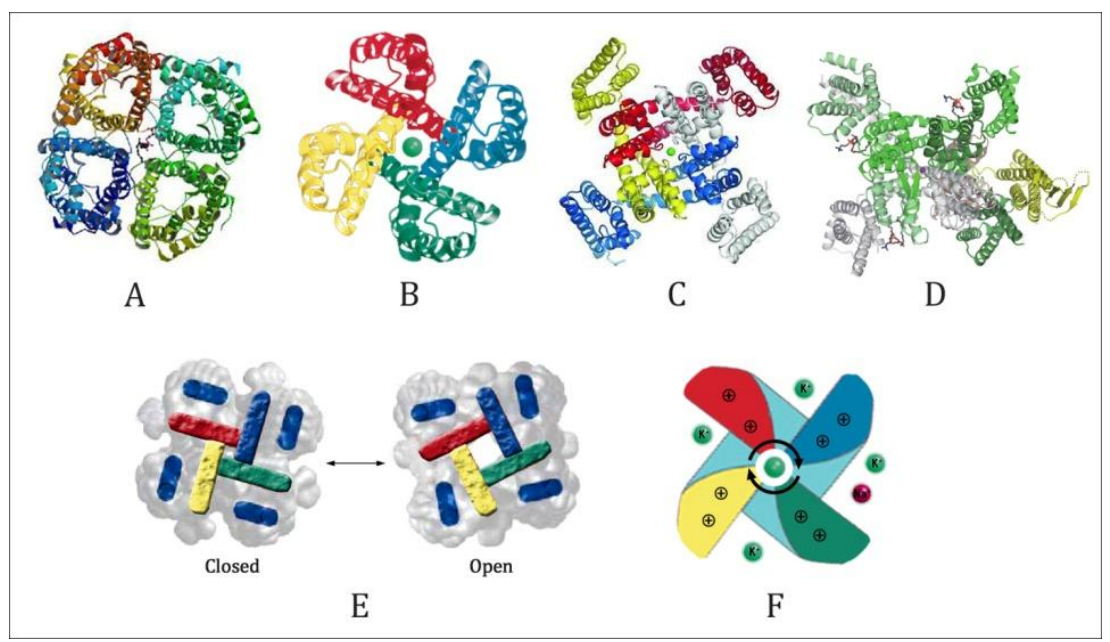

Figure 4 "Same direction sharing" ion channel "origami windmill" model

Fig. A, B, C and D are three-dimensional strip patterns of water channel ${ }^{[63]}, \mathrm{K}^{+}$channel $^{[62]}, \mathrm{Na}^{+}$ channel ${ }^{[64]}$ and $\mathrm{Ca}^{2+}$ channel ${ }^{[65]}$ respectively. Seen from the outside of the cell, they all exist in the cell membrane in the form of tetramer. Fig.E. A model of bacterial $\mathrm{K}^{+}$channel $^{[66]}$. Fig.F. Potassium channel origami windmill model ${ }^{[1]}$.

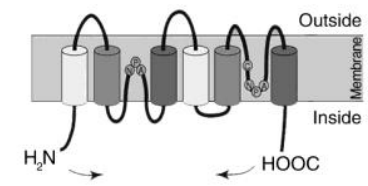

A

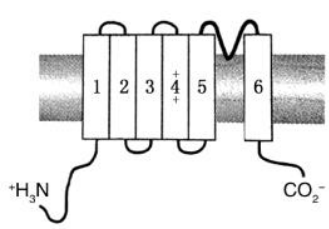

C

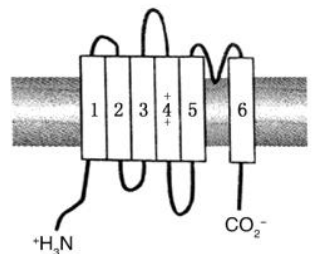

B

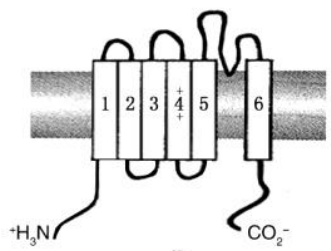

$\mathrm{D}$

Figure 5 Comparison of structural similarity of channel subunits ${ }^{[67,68]}$

Fig. A is $\mathrm{H}_{2} \mathrm{O}$ channel protein "hourglass" model of AQP1, Fig. B, C, D is $\mathrm{K}^{+}$channels, $\mathrm{Na}^{+}, \mathrm{Ca}^{2+}$ channel subunit structure, $\mathrm{H}_{2} \mathrm{O}$ channel and $\mathrm{K}^{+}, \mathrm{Na}^{+}, \mathrm{Ca}^{2+}$ channels, both in the form of four polymers exists in cell membrane, constitute the four polymers each $\alpha$ subunit contains six transmembrane (TM) lipotropy alpha helix $\left(\mathrm{S}_{1}\right.$ to $\left.\mathrm{S}_{6}\right)$, there are three cell outer ring and two cell inner ring. There is a pore domain $(\mathrm{P})$ between the $\mathrm{S}_{5}$ and $\mathrm{S}_{6}$ transmembrane segments. At the narrowest point in the center of the passage $\left(\mathrm{S}_{4}\right)$, the limbic helix contains positively charged arginine separated from each other, and the amino terminus $(\mathrm{N})$ and carboxyl terminus $(\mathrm{C})$ are located in the cell.

$\mathrm{H}_{2} \mathrm{O}$ and $\mathrm{K}^{+}, \mathrm{Na}^{+}, \mathrm{Ca}^{2+}$ may be abide by the principle of channel "Same direction sharing". Agre's work is of great importance and originality, and its inspiration to later scholars to "discover" other so-called "ion channels" may be underestimated. Perhaps, the $\mathrm{K}^{+}, \mathrm{Na}^{+}, \mathrm{Ca}^{2+}$ plasma channels "discovered" later are the " $\mathrm{H}_{2} \mathrm{O}$ channels" of Agra, 
both of which belong to the "E channel". In fact, AQPs of various mammalian aquaporins discovered later, including AQP3, AQP7 and AQP9, are not only permeable to water, but also to glycerol and other small molecules.

The appearance of this kind of situation is similar to "blind people touch the elephant". Agrer used xenopuslaevis oocytes as experimental materials to do experiments. It can prove the existence and function of AQP1. But he thinks that the narrowest part of the channel center is positively charged and can effectively prevent the passage of charged ions. Based on the above, he concluded that the reason why AQP1 is a special protein for water transport is not sufficient, because there are also positive charges on $\mathrm{K}^{+}, \mathrm{Na}^{+}, \mathrm{Ca}^{2+}$ channels. The conclusion of Agre's work led later researchers to mistake the water channels are independent and cannot be "shared" with other ions or molecules. The real situation may be, on the channel with the positive charge of the channel pore formed a blocking pipe, prevent through such channels of cation and contact or stranded on the channel hole, hole wall to ensure the after cationic unimpeded channel, while the front and back into the channel of cation and through the repelling force, pushed the front behind the cationic quickly into the cell.

The diameter of water molecule $(280 \mathrm{pm})$ is almost equal to that of $\mathrm{K}^{+}(276 \mathrm{pm})$. Therefore, we can further speculate that water molecule passing through the cell membrane is also limited. It should "influx and outflow together" with $\mathrm{K}^{+}$. Some experiments have proved that the ion channel is an "aqueous channel", but no experiment can prove that the $\mathrm{H}_{2} \mathrm{O}$ channel "does not allow other ions to pass through".

It should be noted especially that the relationship between membrane potential and ion concentration inside and outside the membrane is relative. When cells are in normal physiological conditions, such as in living cells, according to the "origami windmill" model theory, the most closely related are the cell membrane potential and the area of the inner membrane, the ion diameter on the inner membrane and the number of ions. When cells are in abnormal physiological conditions, such as in vitro cell samples, the cell membrane potential is more related to the volume of cells and the concentration of ions inside and outside cells. The concentration of $\mathrm{K}^{+}$or $\mathrm{Na}^{+}$outside the cell will affect the time course of resting potential and action potential. But it does not change the nature of the descending phase or the ascending phase of the action potential.

For example, when the concentration of extracellular ions is too low, the membrane potential value is related to the cell volume and the amount of water molecules entering the cell. Because water molecules in and out of cells can regulate cell volume and internal osmotic pressure, cell volume will expand due to water, leading to action 
potential in advance. "L channel" belongs to "force sensitive channel", which responds to membrane tension. This expansion force of cell membrane can also be called "repulsive volume force". It changes the intracellular dynamics. When the extracellular fluid is abnormal, if the nerve fibers are put into a solution without $\mathrm{Na}^{+}$, no action potential will be generated, because there is no exchange of $\mathrm{Na}^{+}$and $\mathrm{K}^{+}$on the inner surface of the cell membrane; If you put the nerve fibers in a solution with a very low concentration of $\mathrm{Na}^{+}$, the maximum value of the rising phase of the action potential will decrease, because the $\mathrm{Na}^{+}$is not completely dominant in the rising phase, and $\mathrm{K}^{+}$ is involved too much. When the $\mathrm{Na}^{+}$concentration of extracellular fluid is consistent with that of intracellular $\mathrm{Na}^{+}$, according to the principle of the "origami windmill" model, the measured current cannot be confirmed to be completely $\mathrm{K}^{+}$flow, and the existence of $\mathrm{Na}^{+}$flow cannot be excluded. Similarly, when the $\mathrm{K}^{+}$concentration of extracellular fluid is consistent with that of intracellular $\mathrm{K}^{+}$, according to the principle of the "origami windmill" model, the measured current cannot be confirmed to be completely $\mathrm{Na}^{+}$flow, nor can the existence of $\mathrm{K}^{+}$flow be ruled out.

Paramecium is a single cell protozoa, and its structural characteristics may give us some enlightenment (Figure 6).

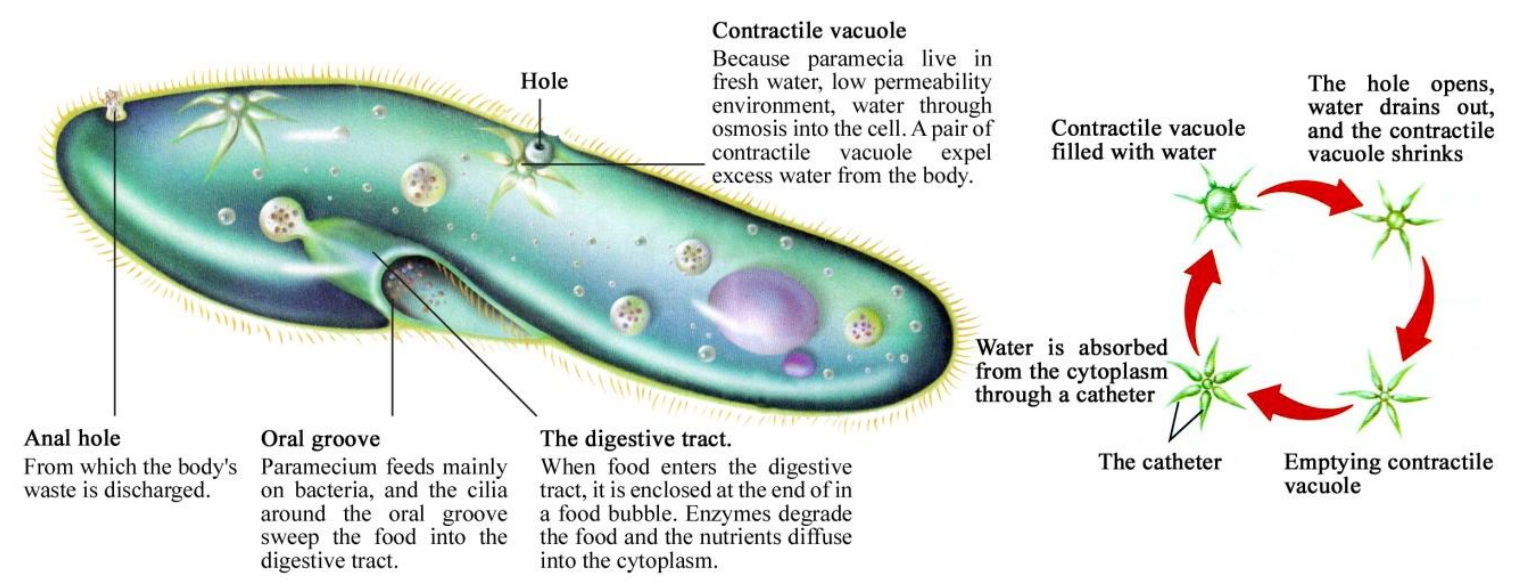

Figure 6 Cell structure of paramecium in unicellular protozoa ${ }^{[35]}$

\subsection{Sodium-potassium pumps, calcium pumps, and so on May not exist}

Applying the ionic theory, the forward deduction cannot be logically self-consistent; the reverse deduction, before the next period can not be reduced to the initial state of action potential. No matter forward reasoning or reverse reasoning, their conclusions prove that the existence of sodium-potassium pump, calcium pump and sodium calcium exchanger is unreasonable. Based on the principle of "origami windmill model", the experimental results of cell action potential are explained reasonably, which do not involve sodium-potassium pump, calcium pump and sodium calcium 
exchanger. It shows that the existence of sodium-potassium pump, calcium pump and sodium calcium exchanger is unnecessary.

According to the theory of origami windmill model, the cell membrane contains at least two kinds of channels, namely "E channel" and "L channel", and the former is "only in no out", while the latter is "only out no in". The Na-K-ATPase and Ca-ATPase on the cell membrane may be the proteins embedded on the cell membrane, which cooperate with the work of $\mathrm{L}$ channel. Their main function is not to play the role of "pump", but to ensure that the water molecules and ions in the cell "only come out and not come in", so as to prevent the cell from swelling and cracking due to the backflow of water molecules. The L channel is much simpler than the e channel, and it may only be the transformation between "closed" and "open" phenomena. For example, when cells are treated with ouabain, which inhibits the $\mathrm{Na}^{+}-\mathrm{K}^{+}$pump, many animal cells swell and often rupture ${ }^{[32]}$. This just shows that when $\mathrm{Na}^{+}-\mathrm{K}^{+}$ATPase is inhibited, the uncontrolled backflow of water molecules from the outside to the inside of the cell leads to the destruction of the "L channel" function.

The absence of sodium-potassium pump, calcium pump and sodium calcium exchanger is reasonable and necessary, which suggests that sodium-potassium pump, calcium pump and sodium calcium exchanger may not exist, and $\mathrm{K}^{+}$leakage channel should belong to "L channel".

\section{Conclusion}

Through combing the basic theories and experiments of cell bioelectricity, the author has basically understood the origin and development of the principles of cell bioelectricity, among which the key figures are Hodgkin, Huxley, Katz, Skou, Deleze and Agre, MacKinnon. The key time nodes that make the problem more and more complex are 1949, 1957, 1960 and 1988, 1998.

The thesis is falsifiable. The method of falsification is very simple, and it comes down to one question, namely: when the cell action potential drops, is $\mathrm{K}^{+}$flowing out or in? If it can be proved that "the falling phase of cell action potential is dominated by $\mathrm{K}^{+}$outflow", all the points in this paper will be invalid. On the contrary, in this paper, a series of illuminating views, will inevitably cause a revolution in the field of life science, involving basic knowledge in the field of life science is not just confined to the content of described in this article, at the same time also prompted the industry don't ignore the physical means, the application of physical means may be an important research direction in the future of mankind's total defeat of major diseases including alzheimer's disease ${ }^{[69,70]}$.

The author is worried about the future of life science. Today's life scientists study 
biological problems on the basis of mathematical models, and regard mathematical models as the real embodiment of the biological world. When the mathematical model is inconsistent with the experimental results, it is not the first to doubt the errors of the mathematical model, but to make the experimental results conform to the mathematical model in the way of "cut one's feet to adapt shoes". The consequence of this approach is a disaster, which leads to a very difficult dilemma for modern life science, and the deeper it gets. Regular of natural science, it should not be "little girl of who lets people dress up as they please".

The accumulation of life science knowledge in 118 years since 1902 seems to have reached a point where it is hard to return. If there are defects in the basic theory, how to correct them? Who will correct it? This is a real problem that life science community must face and cannot avoid. This is related to whether it can help answer the basic biological questions of human health and disease from the source. What's more worrisome is that these controversial "basic knowledge" has been regarded as a "recognized" theory and written into the world's most authoritative excellent higher textbook of life science ${ }^{[26-30]}$ and the mainstream science textbook of high school $^{[21,31-35]}$.

So the author suggests that scholars in the field of life science should re sort out the existing bioelectricity knowledge system-eliminate the false, save the true and clear the source, especially focusing on the papers published by Hodgkin and Huxley in 1952: A quantitative description of membrane current and its application to conduction and excitation in nerve; At the same time, it is necessary to reevaluate the scientificity and scientific value of membrane theory, ionic theory, GHK equation and $\mathrm{H}-\mathrm{H}$ equation, and put forward new theories based on Bernstein membrane theory, and establishing a new mathematical model of cell action potential.

The previous papers published by the author, such as Potassium Channel Origami Windmill Model, Interpretation of Action Potential Generation Mechanism in Cells by Potassium Channel "Origami Windmill" Model, The Theory of Dove-like Particles and Theory of Brain Cell Activation, should be further revised, supplemented and improved according to the contents of this paper.For example, in the work review on Hodgkin and Huxley in The Theory of Dove-like Particles, we need to delete ionic theory, GHK equation, H-H equation and so on.

Finally, it is necessary to explain that since 1994, the author of this article has been engaged in the research of basic theoretical research of brain science and the research and development of encephalopathy rehabilitation equipment, the tasks he has undertaken have been included in the national key new product plan project ${ }^{(}$, the national torch plan industrialization project ${ }^{2}$, and the major scientific and technological 
breakthrough plan project in Heilongjiang ${ }^{(3)}$, he has won the first prize of Heilongjiang Science and Technology Award (invention category) ${ }^{(4)}$ and the first prize of Heilongjiang Excellent New Product ${ }^{(5)}$. He has won many national, provincial and municipal science and technology funds, including Heilongjiang Outstanding Youth Science Fund ${ }^{(}$. The author himself is a technology leader of the leading talent echelon of "biomedical electronics" in Heilongjiang Province ${ }^{(?)}$, the head of Heilongjiang Provincial Brain Disease Rehabilitation Treatment Equipment Engineering Technology Research Center ${ }^{(8)}$, principal of National Postdoctoral research workstation ${ }^{(}$, be selected for the national new century talents project ${ }^{(\mathbb{1}}$, enjoying special allowances of the State Council ${ }^{111}$; Aobo Medical Founder, Dean of Ya'ou Brain Science Institute of Heilongjiang province. Founded in 2001, Ya'ou Brain Science Institute of Heilongjiang province is an independent legal entity and a professional academic research institution supported by Harbin Aobo Medical Devices Co., Ltd., focusing on basic theoretical research of brain science.

\section{References:}

[1] Sun ZD. Potassium Channel Origami Windmill Model. Journal of US-China Medical Science, 2019, 16(4): 1-4.

[2] Jiao MD, Sun ZD. Effects of Aobo brain function rehabilitation instrument on cerebral circulation and brain function. Medicine Healthcare Apparatus, 1998, 3: 251-52.

[3] Tian NN. Application of Aobo brain function rehabilitation instrument in post-troke hemiplegia patients. Chinese Journal of Medical Device, 2009, 9: 68.

Note: (1)Transcranial magnetoelectric depression insomnia treatment instrument (project number: 2011TJB21022), Ministry of Science and Technology of China, 2011.(2)Transcranial Magnetoelectric Depressive Insomnia Treatment Instrument (Project No. 2012GH040294), Ministry of Science and Technology of China, 2012.(3) Development of tDCS Brain Function Rehabilitation Therapy Apparatus(Project No.: GC13C118), Certificate of Scientific and Technological Achievement Identification: Heikechengjianzi [2016] No. 005. Transcranial magnetoelectric encephalopathy treatment instrument(Parkinson Therapeutic Apparatus) (Project Number: GB09C401), Scientific and Technological Achievement Appraisal Certificate: Heikechengjianzi [2011] No. 27, Development and Application of Transcranial Magnetoelectric Dementia Treatment Instrument (GC12C112), Heike Chengjianzi [2014] No. 34.(4)Heilongjiang Province Science and Technology Invention First Prize (Certificate Number: 2013030), Heilongjiang Provincial People's Government, 2013.(5) Transcranial magnetoelectric depression insomnia treatment instrument (Project No. 2011TJB21022), Heilongjiang Provincial Government, 2011. (6) National innovation fund project acceptance certificate, national innovation fund project approval certificate:Transcranialmagnetoelectric encephalopathy treatment instrument(Project code: 12C26212301482); The Heilongjiang Provincial Outstanding Youth Science Fund was awarded by the Heilongjiang Provincial Natural Science Foundation in 2006.(7)Heilongjiang Provincial Department of Human Resources and Social Security, 2017; "Two butterflies" dancing in the spring of science, Science and Technology Daily, 2013-02-25. 8)Science and Technology Department of Heilongiiang Province, 2013. 9Ministry of Human Resources and Social Security, 2013. (10Ministry of Personnel, Ministry of Science and Technology, etc., 2006; Three scholars from our province were selected into the second national "New Century Million Talent Project", Heilongjiang Daily, 2006-12-07; (11) State Council, certificate number: 9230627, 2007. 
[4] Harbin Successfully Develops the First Therapeutic Instrument for Depression in the World. Science-Technology\& Publication, 2011, 6: 127.

[5] Zou W, Tang Q, Sun ZD, et al. Clinical Study on Transc-ranial Magnetoelectric Depression Treatment Instrument Treatmenting Depression. viXra.org, viXra:1707.0026, 2017-07-04.

[6] Xing XL, Tang Q. Clinical research on influences of transcranial magnetoelectric stimulation on Parkinson's disease.(The assembly of conference papers of the 11th national rehabilitation academic conference of Exercise Therapy Branch of Chinese Association of Rehabilitation Medicine, 2011).

[7] Tang Q, Zou W, Sun ZD, et al. Clinical study on Transcranial magnetoelectric encephalopathy treatment instrument treatmenting parkinson's disease. Beijng: Sciencepaper Online[2017-02-08]. http://www.paper.edu.cn/releasepaper/content/201702-38.

[8] Tang Q, Zou W, Sun ZD, et al. Clinical study on transcranial magnetoelectric encephalopathy treatment instrument for Alzheimer's disease. Highlights of Sciencepaper Online, 2017, 10(11): 1216-1222.

[9] Successful development of the first therapeutic instrument for Alzheimer disease in the world. Science Technology \& Publication, 2014, 6: 143.

[10] Sun ZD. The Theory of Brain Cell Activation. Journal of US-China Medical Science, 2017, 14(5): 203-211.

[11] Sun ZD. The Theory of Dove-like Particles. Journal of US-China Medical Science, 2019, 16(2): 73-99.

[12] Sun ZD. Interpretation of Action Potential Generation Mechanism in Cells by Potassium Channel “Origami Windmill” Model. Journal of US-China Medical Science, 2019, 16(4): 1-7.

[13]Sun ZD. Explain the mechanism of myocardial cell action potential with $\mathrm{K}^{+}$channel "origami windmill" mode. Beijng: National Science and Technology Library[2020-05-22]. https://preprint.nstl.gov.cn/preprint/main.html?action=showFile\&id=8a8b8a986ec502f301723b562f $3807 \mathrm{~b} 5$.

[14] Hodgkin AL, Katz B. The effect of sodium ions on the electrical activity of the giant axon of the squid. J Physiol, 1949, 108:37-77.

[15] Bernstein J. Untersuchungen zur Thermodynamik der bioelektrischen Ströme. Pflüg Arch, 1902, 92:521-562.

[16] Nassonov DN, Насонов ДН. Местная реакция протоплаэмы и распространяю щееся воэбуждение Иэд АН. СССР, 1959.

[17] Wang BY. Neuroelectrophysiology. Beijing: People's education Press, 1982.

[18] Hodgkin AL, Huxley AF. Action Potentials Recorded from Inside a Nerve Fibre. Nature, 1939, 144(3651):710-711.

[19] Goldman DE. Potential, impedance, and rectification in membranes. J Gen Physiol, 1943, 27:37-60.

[20] Hodgkin AL, Huxley AF. Current carried by sodium and potassium ions through the membrane of the giant axon of Loligo. The Journal of Physiology, 1952, 116(4):449-472.

[21] Philips R, Kondev J, Theriot J. Physical Biology of the Cell. Beijing: Science Press, 2012.

[22] Nguyen MK. Quantitative interrelationship between Gibbs-Donnan equilibrium, osmolality of body fluid compartments, and plasma water sodium concentration. Journal of Applied Physiology, 2005, 100(4):1293-1300.

[23] Feiner AS, Mcevoy AJ. The Nernst Equation. Journal of Chemical Education, 1994, 71(6):493. 
[24] Goldman DE. Potential, impedence, and rectification in membranes. The Journal of General Physiology, 1943, 27(1): 37-60.

[25] Hodgkin AL, Huxley AF. A quantitative description of membrane current and its application to conduction and excitation in nerve. The Journal of Physiology, 1952, 117: 500-544.

[26] Bear MF, Connors BW, Paradiso MA. Neuroscience: Exploring the Brain. 2th ed. Philadelphia: Lippincott Williams \& Wilkins, 2004.

[27] Kandel ER, Schwartz JH, Jessell T M, et al. Principles of Neural Science, 5th Edition. New York: The Mcgraw-Hill Education, 2013.

[28] Prutchi D, Norris M. Design and Development of Medical Electronic Instrumentation: A Practical Perspective of the Design, Construction, and Test of Medical Devices. New York: John Wiley \& Sons, 2005.

[29] Robinson AJ, Mackle LS. Clinical Electrophysiology. 3th ed. Philadelphia: Lippincott Williams \& Wilkins, 2011.

[30] Conn PM. Essential Ion Channel Methods. Amsterdam : Elsevier Inc, 2010.

[31] Alberts B, Bray D, Hopkin K, et al. Essential Cell Biology. 3th ed. Boca Raton: CRC Press Inc, 2009.

[32] Alberts B. Molecular Biology of The Cell. 4th ed. Beijing: Science Press, 2008, 682-724.

[33] Weaver RF. Molecular Biology. 5th ed. Beijing: Science Press, 2013.

[34] Nicholls JG, Martin AR, Fuchs PA, et al. From Neuron to Brain. 5th ed. Beijing: Science Press, 2014.

[35] Alton B. Biology/The Dynamics of Life. Hangzhou: Zhejiang Education Publishing House, 2008.

[36] Curtis HJ, Cole KS. Membrane resting and action potentials from the squid giant axon. J Cell Comp Physiol, 1949, 19: 135.

[37] Ling G, Gerard RW. The normal membrane potential of frog Sartorius fibres. Jour Cell Ani Comp Physiol, 1949, 34(3):383-396.

[38] Huxley AF, Stämpfli R. Direct determination of membrane resting potential and action potential in single myelinated nerve fibres. Journal of Physiology, 1951, 112.

[39] Huxley AF, StäMpfli R. Effect of potassium and sodium on resting and action potentials of single myelinated nerve fibres. Journal of Physiology, 1951, 112(3-4):496-508.

[40] Lorente de Nó R. A study of nerve physiology. Studies from the Rockefeller Institute for Medical Research, 1947, 131-132.

[41] Feng TP, Liu YM. The connective tissue sheath of the nerve as effective diffusion barrier. Jour Cell \& Comp Physiol, 1949, 34(1):1-16.

[42] Feng TP, Liu YM. The concentration-effect relationship in the depolarization of amphibian nerve by potassium and other agents. Journal of Cellular Physiology, 1949, 34(1):33-42.

[43] Feng TP, Liu YM. The membrane potential of potassium depleted nerve[J]. Chinese J Physiol, 1951, 18: 61.

[44] Feng TP, Liu YM. Further study on depolarization of nerve by potassium. Chinese J Physiol,1953, 19: 25.

[45] Adrian RH. The Effect of Internal and External Potassium Concentration on the Membrane Potential of Frog Muscle. Journal of Physiology, 1956, 133(3): 631-658.

[46] Baker PF, Hodgkin AL, Shaw TI. Replacement of the axoplasm of giant nerve fibres with artificial solutions. Journal of Physiology, 1962, 164(2):330-354. 
[47] Hodgkin AL, Huxley AF, Katz B. Measurements of current-voltage relations in the membrane of the giant axon of Loligo. J Physiol, 1952, 116: 424.

[48] Liu TP. Myocardial electrophysiology. Beijing: Peking University Press, 1988.

[49] Krogh A. The use of isotopes as indicators in biological research. Science, 1937, 85(2199): 187-191.

[50] Dean R. Theories of electrolyte equilibrium in muscle. Biological symposia, 1941, 3: 331-348.

[51] Conway EJ. Nature and significance of concentration relations of potassium and sodium ions in skeletal muscle. Physiological Reviews, 1957, 37(1): 84-132.

[52] Skou JC. The influence of some cations on an adenosine triphosphtase from peripheral nerves. Biochim Biophys Acta, 1957, 23: 394-401.

[53] Deleze J. Possible reasons for drop of resting potential of mammalian heart preparations during hyphothermia. Circulation Research, 1960, 8(3):553-557.

[54] Hodgkin AL, Huxley AF. Potassium leakage from an active nerve fibre[J]. Journal of Physiology, 1947, 106(3).

[55] Gu FJ. Hodgkin: Maxwell in the neuroscience community. World of Science, 2018, 124-127.

[56] Ebashi S, Lipmann F. Adenosine triphosphate linked concentration of calcium ions in a particulate fraction of the rabbit muscle. J Cell Biol, 1962, 14:389-400.

[57] Reuter H, Seitz N. The dependence of calcium efflux from cardiac muscle on temperature and external ion composition. The Journal of Physiology, 1968, 195(2): 451-470.

[58] Hilgemann DW. Regulation and deregulation of cardiac Na+-Ca2+ exchange in giant excised sarcolemmal membrane patches. Nature, 1990, 344: 242-245.

[59] Kopernik N. De Revolutionibus Orbium Coelestium. Beijing: Peking University Press, 2006.

[60] Perez AG, Budvytyte R, Lars D, et al. Penetration of Action Potentials During Collision in the Median and Lateral Giant Axons of Invertebrates. Physical Review X, 2014, 4(3), DOI: 10.1103/PhysRevX.4.031047

[61] Denker BM, Smith BL, Kuhajda FP, Agre P. Identification, purification, and partial characterization of a novel $\mathrm{Mr} 28,000$ integral membrane protein from erythrocytes and renal tubules. The Journal of Biological Chemistry, 1988, 263, 15634-15642.

[62] Doyle DA, João Morais Cabral, Pfuetzner RA, et al. The Structure of the Potassium Channel: Molecular Basis of $\mathrm{K}^{+}$Conduction and Selectivity. Science, 1998, 280(3): 69-77.

[63] Han YR. Molecular cell biology. 4th ed. Beijing: Science Press, 2012.

[64] Zhang X, Ren W, DeCaen P, et al. Crystal structure of an orthologue of the NaChBac voltage-gated sodium channel. Nature, 2012, 486, 130-134.

[65] Wu J, Yan Z, Li Z, et al. Structure of the voltage-gated calcium channel Cav1.1 complex. Science, 2015, 350(6267): $\operatorname{aad} 2395$.

[66] Perozo E. Structural Rearrangements Underlying K+-Channel Activation Gating. Science, 1999, 285(5424):73-78.

[67] Agre P, King L S, Yasui M, et al. Aquaporin water channels-from atomic structure to clinical medicine. Journal of Physiology, 2002, 542:3-16.

[68] Han JS. Neuro Science. 3rd ed. Beijing: Peking university medical press, 2009.

[69] Fang Y. Chinese scientists have made new breakthroughs in the field of basic theoretical research in brain science. People's Daily, 2019-10-17.

[70] Zhang SJ. Heilongjiang scholars reasonably explain the whole process of action potential. Guangming Daily, 2019-10-16. 